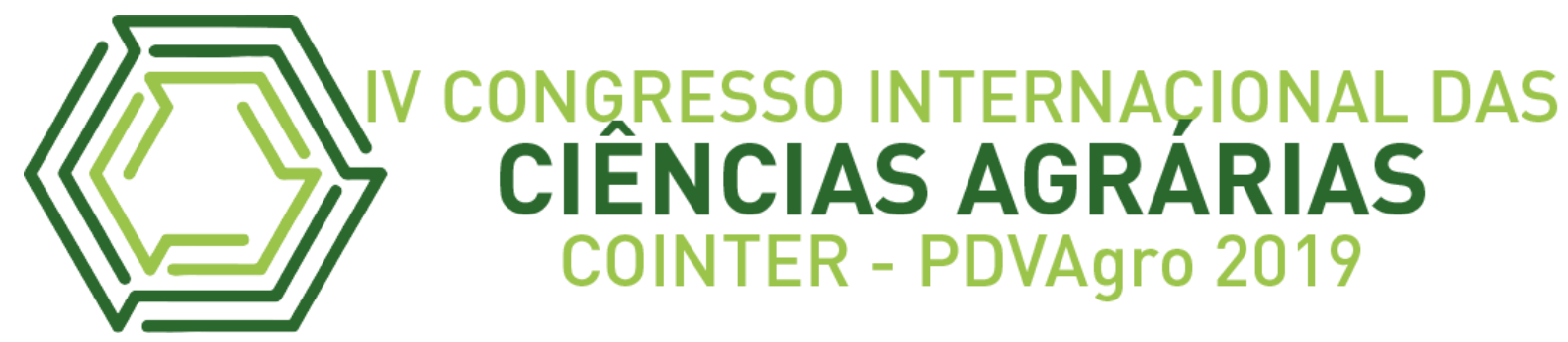

\title{
INFLUÊNCIA DA ADUBAÇÃO ORGÂNICA E MINERAL E DIFERENTES NÍVEIS DE DENSIDADES NA PRODUTIVIDADE E QUALIDADE DE RAIZES DE RABANETE
}

\section{INFLUENCIA DE LA FERTILIZACIÓN ORGÁNICA Y MINERAL EN DIFERENTES NIVELES DE DENSIDAD NA PRODUCTIVIDAD Y CALIDAD DEL RABANETE}

\section{INFLUENCE OF ORGANIC AND MINERAL FERTILIZATION ON DIFFERENT LEVELS OF DENSITIES IN THE PRODUCTIVITY AND QUALITY OF RABANETE.}

\author{
Apresentação: Comunicação Oral
}

SILVA, Clélia Brasil Soares da ${ }^{1}$; GOMES, Francisco Mateus Medina²; SANTOS, Carla Araújo $^{3}$; ARAÚJO, Daniel Barbosa ${ }^{4}$

\section{DOI: https://doi.org/10.31692/2526-7701.IVCOINTERPDVAgro.2019.0033}

\begin{abstract}
Resumo
O rabanete (Raphanus Sativus L.) caracteriza-se como uma cultura de ciclo curto tornando-se uma excelente opção para os pequenos produtores que necessitam de um retorno rápido de sua produção, possuindo ainda inúmeras qualidades nutricionais e medicinais. Sabe-se que o desenvolvimento das hortaliças, em geral, está associado ao estado nutricional da cultura, sendo esse afetado diretamente pela fertilidade do solo e concorrência entre plantas. Diante disto, o presente estudo teve como objetivo, analisar a influência da adubação (orgânica e mineral) e diferentes espaçamentos na produtividade e qualidade de raízes de rabanete. $\mathrm{O}$ experimento foi conduzido em campo experimental do Instituto Federal de Educação, Ciencia e Tecnologia do Maranhão - Campus Codó, com delineamento experimental em blocos casualizados (DBC), e esquema fatorial $3 \times 4$, sendo 3 tipos de adubos (húmus de esterco caprino, esterco bovino e NPK), 4 densidades $15 \mathrm{~cm} \times 4 \mathrm{~cm}, 15 \mathrm{~cm} \times 7 \mathrm{~cm}, 20 \mathrm{~cm} \times 4 \mathrm{~cm}$ e $20 \mathrm{~cm} \times 8 \mathrm{~cm}$ (testemunha), em 3 repetições, compreendendo um total de 12 tratamentos. Os parâmetros avaliados foram: produtividade total de raiz (PTR); produtividade comercial de raiz (PCR) e diâmetro de raiz (DR). Após a obtenção das médias, as variáveis foram submetidas ao teste $\mathrm{F}$, e em caso de

\footnotetext{
${ }^{1}$ Bacharelado em Agronomia, pelo Instituto Federal de Educação Ciência e Tecnologia do Maranhão - IFMA Campus Codó. cleliabrasil2017@gmail.com.

${ }^{2}$ Bacharelado em Agronomia, pelo Instituto Federal de Educação Ciência e Tecnologia do Maranhão - IFMA Campus Codó. mateus.medina@acad.ifma.edu.br.

${ }^{3}$ Bacharelado em Agronomia, pelo Instituto Federal de Educação Ciência e Tecnologia do Maranhão - IFMA Campus Codó. Carlaaraújo377@gmail.com.

${ }^{4}$ Prof. Dr. Em Ciência do Solo do Instituto Federal de Educação Ciência e Tecnologia do Maranhão - IFMA Campus Codó, daniel.araujo@ifma.edu.br.
} 
significância, ao teste de Tukey a $1 \%$ de probabilidade para comparação das médias. $\mathrm{O}$ espaçamento de $20 \mathrm{~cm} \times 8 \mathrm{~cm}$ mostrou-se ser o melhor para o cultivo de rabanete, independente do adubo utilizado, sendo que o humus de minhoca apresentou as melhores médias para todos os parâmetros analisados e o NPK os resultados mais ínferos, onde os melhores resultados foram do tratamento com humus de minhoca e espaçamento $20 \mathrm{~cm}$ x $8 \mathrm{~cm}$. Foi observado que o espaçamento $15 \mathrm{~cm} \times 7 \mathrm{~cm}$ obteve resultados mais aproximados do melhor tratamento e que o espaçamento $15 \mathrm{~cm} \mathrm{x} 4 \mathrm{~cm}$ apresentou resultados inferiores a todos os demais espaçamentos, evidenciando que nas condições em que o experimento foi conduzido, o espaçamento entre plantas foi o que mais limitou a produtividade da cultura.

Palavras-Chave: Raphanus Sativus L.; Espaçamentos; Adubação; Produção.

\title{
Resumen
}

El rábano (Raphanus sativus L.) se caracteriza por ser un cultivo de ciclo corto, por lo que es una excelente opción para los pequeños productores que necesitan un rápido retorno de su producción, ya que tienen numerosas cualidades nutricionales y medicinales. Se sabe que el desarrollo de vegetales en general está asociado con el estado nutricional del cultivo, que se ve directamente afectado por la fertilidad del suelo y la competencia entre las plantas. Por lo tanto, el presente estudio tuvo como objetivo analizar la influencia de la fertilización (orgánica y mineral) y diferentes espaciamientos en la producción y calidad de la raíz de rábano. El experimento se realizó en el campo experimental del Instituto Federal de Educación, Ciencia y Tecnología de Maranhão - Campus Codó, con un bloque de dibujo de bloques al azar (DBC) y un esquema factorial $3 \times 4$, compuesto de 3 tipos de fertilizantes (estiércol de humus de cabra, estiércol bovino y NPK), 4 densidades $15 \mathrm{~cm}$ x $4 \mathrm{~cm}, 15 \mathrm{~cm} \mathrm{x} 7 \mathrm{~cm}, 20 \mathrm{~cm}$ x $4 \mathrm{~cm}$ y $20 \mathrm{~cm}$ x 8 $\mathrm{cm}$ (control), en 3 repeticiones, que comprenden un total de 12 tratamientos. Los parámetros evaluados fueron: productividad total de la raíz (PTR); Productividad de la raíz comercial (PCR); Diámetro de la raíz (DR). Después de obtener las medias, las variables se sometieron a la prueba $\mathrm{F}$ y, en caso de importancia, a la prueba de Tukey con una probabilidad de $1 \%$ para la comparación de las medias. El espaciado de $20 \mathrm{~cm} \mathrm{x} 8 \mathrm{~cm}$ demostró ser el mejor para cultivar rábanos, independientemente del fertilizante utilizado, y el humus de lombrices presentó los mejores medios para todos los parámetros analizados y las puntuaciones NPK más bajas, donde se obtuvieron los mejores resultados Tratamiento con humus de lombriz y un espacio de $20 \mathrm{~cm}$ x $8 \mathrm{~cm}$. Se observó que se obtuvo la separación de $15 \mathrm{~cm}$ x $7 \mathrm{~cm}$ resultados más aproximados el mejor tratamiento y la separación de $15 \mathrm{~cm} \mathrm{x} 4 \mathrm{~cm}$ mostró resultados inferiores a todas las otras separaciones, que muestra que las condiciones en que el experimento se llevó a cabo La separación entre plantas fue lo que más limitó la productividad de los cultivos.

Palabras Clave: Raphanus Sativus L.; Espaciamiento; Fertilización; Produccion.

\begin{abstract}
Radish (Raphanus sativus L.) is characterized as a short cycle crop, making it an excellent choice for small producers who need a quick return of their production, possessing numerous nutritional and medicinal qualities. It is known that the development of vegetables in general is associated with the nutritional status of the crop, which is directly affected by soil fertility and competition between plants. Therefore, the present study aimed to analyze the influence of fertilization (organic and mineral) and different spacing on yield and quality of radish root. The
\end{abstract}


experiment was conducted in an experimental field of the Federal Institute of Education, Science and Technology of Maranhão - Campus Codó, with randomized block design (DBC) and $3 \times 4$ factorial scheme, being 3 types of fertilizers (goat manure, organic fertilizer manure and NPK ), 4 densities $15 \mathrm{~cm} \times 4 \mathrm{~cm}, 15 \mathrm{~cm} \times 7 \mathrm{~cm}, 20 \mathrm{~cm} \times 4 \mathrm{~cm}$ and $20 \mathrm{~cm} \times 8 \mathrm{~cm}$ (control), in 3 replications, totaling 12 treatments. The parameters evaluated were: total root productivity (PTR); Commercial root productivity (PCR); Root Diameter (DR). After obtaining the means, the variables were submitted to the $\mathrm{F}$ test and, in case of significance, the Tukey test at $1 \%$ probability for comparison of the means. The spacing of $20 \mathrm{~cm} \times 8 \mathrm{~cm}$ was the best for radish cultivation, regardless of the fertilizer used, and humus presented the best averages for all analyzed parameters and the NPK had the lowest results, where the best results were treatment with earthworm humus and spacing $20 \mathrm{~cm} \times 8 \mathrm{~cm}$. It was observed that the $15 \mathrm{~cm} \times 7 \mathrm{~cm}$ spacing obtained more approximate results of the best treatment and that the spacing of $15 \mathrm{~cm}$ $\mathrm{x} 4 \mathrm{~cm}$ presented results inferior to all other spacings, showing that under the conditions under which the experiment was conducted, spacings between plants was what most limited crop productivity.

Keywords: Raphanus Sativus L.; Spacing; Fertilizing; Production.

\section{Introdução}

A produção de hortaliças exerce um papel de fundamental importância na economia e na agricultura brasileira. As hortaliças constituem um grande grupo de plantas alimentares que se caracterizam pelo alto valor nutritivo, pequeno porte e rápido crescimento (EMBRAPA, 2009). O rabanete (Raphanus sativus. L), pertencente à família Brassicaceae, é uma das culturas hortícolas mais primitivas que se possui registro, presumindo-se que já era cultivada há mais de três milênios, contudo, sua origem é bastante contestada, suspeitando-se ser oriunda da China, sul da Europa e até do antigo Egito.

As raízes desta hortícola tuberosa apresentam expressiva divergência entre suas formas e tamanhos, podendo estas serem ovais, alongadas ou redondas, e coloração da casca vermelha ou branca, e sua polpa habitualmente branca. O rabanete é abundante em fibras alimentares, vitamina $\mathrm{C}$ e minerais como o potássio e fósforo. Concede numerosos benefícios à saúde como: prevenção ao câncer, diminuição do colesterol, ajuda na digestão, na regulação da pressão arterial, além de contribuir para um melhor funcionamento renal e possibilitando, ainda, redução de peso (ASSIS et al., 2016).

A produtividade de rabanete no Brasil no ano de 2006 foi de 10.489 toneladas, sendo que na região nordeste representou cerca de 257 toneladas, onde o maranhão obteve uma produção equivalente a 11 toneladas (IBGE, 2006). 
Segundo Oliveira et al., (2013) no Brasil, a produção de hortaliças tem aumentado nos últimos anos, tornando o consumidor bastante exigente em termos de qualidade, fazendo com que os produtores adotem novas tecnologias e manejos que aumentem a qualidade e rendimento das culturas. Diante do exposto, a adubação a base de estercos de animais, vermicompostagem, e adubos químicos representam uma alternativa viável para os produtores, presente na maioria das propriedades rurais, e por serem de baixo custo. Sendo esses, ricos em nutrientes disponibilizando-os por todo o crescimento da cultura, minimizando os ricos de erosão, aumentando as qualidades químicas e físicas do solo, propiciando macros e micronutrientes as cultivares (KIEHL, 2010).

Os adubos orgânicos de origem bovina segundo (Moreira et al., 2015) são os mais utilizados pelos produtores no cultivo de hortaliças. $\mathrm{O}$ aproveitamento de esterco bovino tornase uma prática útil e econômica para os pequenos e médios produtores, sendo este rico em nutrientes como nitrogênio fosforo e potássio, disponibilizando-os para as plantas (OLIVEIRA et al., 2007). Outra fonte de adubo tão eficiente quanto ao esterco bovino e economicamente viável aos produtores é o humus de minhoca, podendo este ser obtido de qualquer resíduo orgânico, apresentando na sua composição alto teor de matéria orgânica, reconstituinte da estrutura física e biológica do solo que neutraliza o $\mathrm{pH}$, além de aumentar a resistência das plantas contra pragas e doenças (FREITAS, 2017).

$\mathrm{Na}$ adubação mineral são utilizados fertilizantes, geralmente sais, altamente solúveis e dependentes de algum processo industrial para sua obtenção (ISHERWOOD, 2000). O NPK mais conhecido adubo químico, e mais utilizado pelos agricultores, possui os nutrientes essenciais para o desenvolvimento das plantas, disponibilizando-os de forma mais rápida no solo para absorção das raízes pela planta.

Outro fator de fundamental importância a se considerar no tamanho de hortaliças é a escolha do espaçamento adequado, já que este pode influenciar no desenvolvimento tanto da espécie, quanto no ataque de doenças a cultivar (PASQUALOTTO et al., 2014).

Segundo Moraes (2006) o espaçamento, é um fator de grande relevância a ser considerado durante o cultivo de hortaliças, visto que este pode interferir no período de crescimento, no estabelecimento do tempo para a colheita, bem como, na tolerância do produto às condições de manuseio e de armazenamento. $\mathrm{O}$ uso adequado de uma população de plantas por área é essencial para se evitar carência de minerais e de água e para se obter uma boa produtividade. 
Perante o descrito, objetiva-se com o presente estudo analisar o desempenho produtivo do rabanete em função de diferentes adubos e níveis de densidades, visando proporcionar alta produtividade dessa cultura, com possível redução de custos ao produtor.

\section{Fundamentação Teórica}

O rabanete (Raphanus sativus L.) caracteriza-se como uma das cultivares de ciclo mais curto dentre as hortaliças, o que a torna uma boa opção para o produtor rural, rico em vitaminas e minerais, possuindo valores medicinais usada principalmente em salada e fins decorativos e apresenta uma alta demanda na indústria horteleira.

A busca por uma alimentação saudável, e um manejo mais sustentável, levou a um aumento no cultivo de alimentos orgânicos. Maia Filho et al., (2010) citado por Bonela et al. (2017) ressalta que atualmente a demanda por produtos livres de insumos artificiais e agroquímicos, tem crescido de forma significativa, em decorrência da preocupação por uma melhoria na qualidade de vida minimizando os impactos causados ao solo. E que o aproveitamento, de insumos de origem naturais, como os estercos de bovinos e biofertilizantes, deve ser incentivado tanto na pulverização das plantas como na aplicação direta no solo. Silva et al., (2017) acrescenta ainda, que a adoção de métodos mais sustentáveis que não prejudicam o meio ambiente vem proporcionando os agricultores, principalmente os de base familiar a alcançar um mercado de produtos diferenciados, mediante a redução na aplicação de adubos e defensivos sintéticos, visto que insumos localmente disponíveis exercem um papel de grande significância na formação desse agrossistema.

Conhecendo-se a importância que a adubação representa para o aumento na qualidade e produtividade final das culturas agrícolas, e que estas necessitam de um aporte significativo de nutrientes, o emprego de adubos de base orgânica, torna-se uma alternativa viável ao produtor, já que estes podem ser encontrados facilmente nas propriedades rurais.

Conforme Batista (2011) as hortaliças necessitam de quantidades significativas de nutrientes, especialmente de nitrogênio e potássio. Sendo estes, fundamentais para o crescimento da parte aérea como, também, das raízes, o modo mais utilizado para atender essa demanda de nutrientes é por meio de fertilizantes químicos, entretanto, os custos exacerbados com estes adubos e as consequências negativas que eles provocam ao solo, levam o agricultor a recorrer a outras opções. Edvan e Carneiro (2011) afirmam que a aplicação de adubos naturais é bastante viável na diminuição do custo com fertilizantes químicos na lavoura, dessa forma 
proporcionando maior economia dos recursos naturais além de contribuir para melhoria do meio ambiente.

Nessa perspectiva silva et al., (2001) afirma que o aproveitamento de estercos de animais e compostos orgânicos vem sendo amplamente utilizada como adubação orgânica nas lavouras de olerícolas a fim de reduzir a quantidade de fertilizantes químicos e consequentemente, melhorando as qualidades físicas, químicas e biológicas do solo. De acordo com Souza e Resende (2003), adubos orgânicos produzidos com matéria prima de origem animal, vegetal e industrial são recomendados para o cultivo de hortaliças, por serem ricos em nutrientes, principalmente em nitrogênio.

Dentre esses destaca-se os de origem animal como o esterco bovino. Vitti et al., (2007), constatou que o efeito da aplicação de composto de origem bovina na lavoura do rabanete influenciou positivamente o desenvolvimento tanto da parte aérea, como da raiz do rabanete, indicando sua superioridade a outros estercos.

De acordo com Medeiros (2014) as adubações, orgânica e química, exercem influencias significativas nas características físico-químicas da cultivar, podendo ainda provocar alterações nas propriedades químicas do solo de modo a alterar a sua qualidade.

Na adubação química as principais vantagens desses fertilizantes são a disponibilidade imediata de nutrientes para culturas de ciclo anual, alta concentração de nutrientes e facilidade de manuseio, no entanto, seu uso por longos períodos e grandes quantidades, contribui para alterações nas propriedades químicas e biológicas do solo, e dependendo da magnitude pode causar estresses na planta, comprometendo tanto a qualidade nutricional dos alimentos, como também levando a um esgotamento do potencial produtivo do solo (CUSTÓDIO 2014).

Tendo em vista os benefícios dos adubos oriundos de resíduos orgânicos, no qual proporcionam alterações positivas nas características química, física e biológica do solo, estes atuam minimizando a quantidade e gastos com insumos químicos, promovem ainda a produção de alimentos saudáveis e que não degradam o solo (CERQUEIRA JÚNIOR et al., 2013).

Oliveira (2001) classifica o vermicomposto como fonte de matéria orgânica na produção de hortaliças, uma ótima opção aos agricultores, por se tratar um fertilizante orgânico obtido pela decomposição aeróbia controlada, rico em macro e micronutrientes, atuando de forma benéfica sobre o solo, favorecendo a sua conservação e auxiliando o desenvolvimento das plantas 
Outro quesito de fundamental importância, com influencias significativas na produtividade, é a escolha de um espaçamento, adequado na produção de hortaliças, visto que este, pode promover um melhor aproveitamento de área. Segundo Reis et al (2010) na busca por tornar mais rentável a produção, deve-se considerar o espaçamento, a vista disso um método óbvio de ampliar o rendimento de uma cultura é plantar um total maior de plantas por unidade de área. Todavia, em geral, a adoção deste método visando aumentar a produtividade possui uma limitação, observando que, com a ampliação na densidade de população, a concorrência entre plantas por nutrientes cresce, prejudicando o desenvolvimento individual, podendo, até mesmo, ocorrer queda no desempenho e/ou na qualidade.

\section{Metodologia}

O experimento foi conduzido no Instituto Federal de Educação, Ciência e Tecnologia do Maranhão - IFMA/Campus Codó-MA. Localizado no Povoado Poraquê Zona Rural, a 5 km da sede do município de Codó, este localizado na Região dos Cocais Maranhenses com coordenadas geográficas $4^{\circ} 26^{\prime} 51^{\prime}$ ' S e $43^{\circ} 52^{\prime} 57^{\prime}$ ' W e altitude de 48 metros, clima tropical e precipitação média anual de 1526 mm, durante o período de Setembro de 2018 a Agosto de 2019.

Figura 1 - Mapa de localização de Codó - MA.

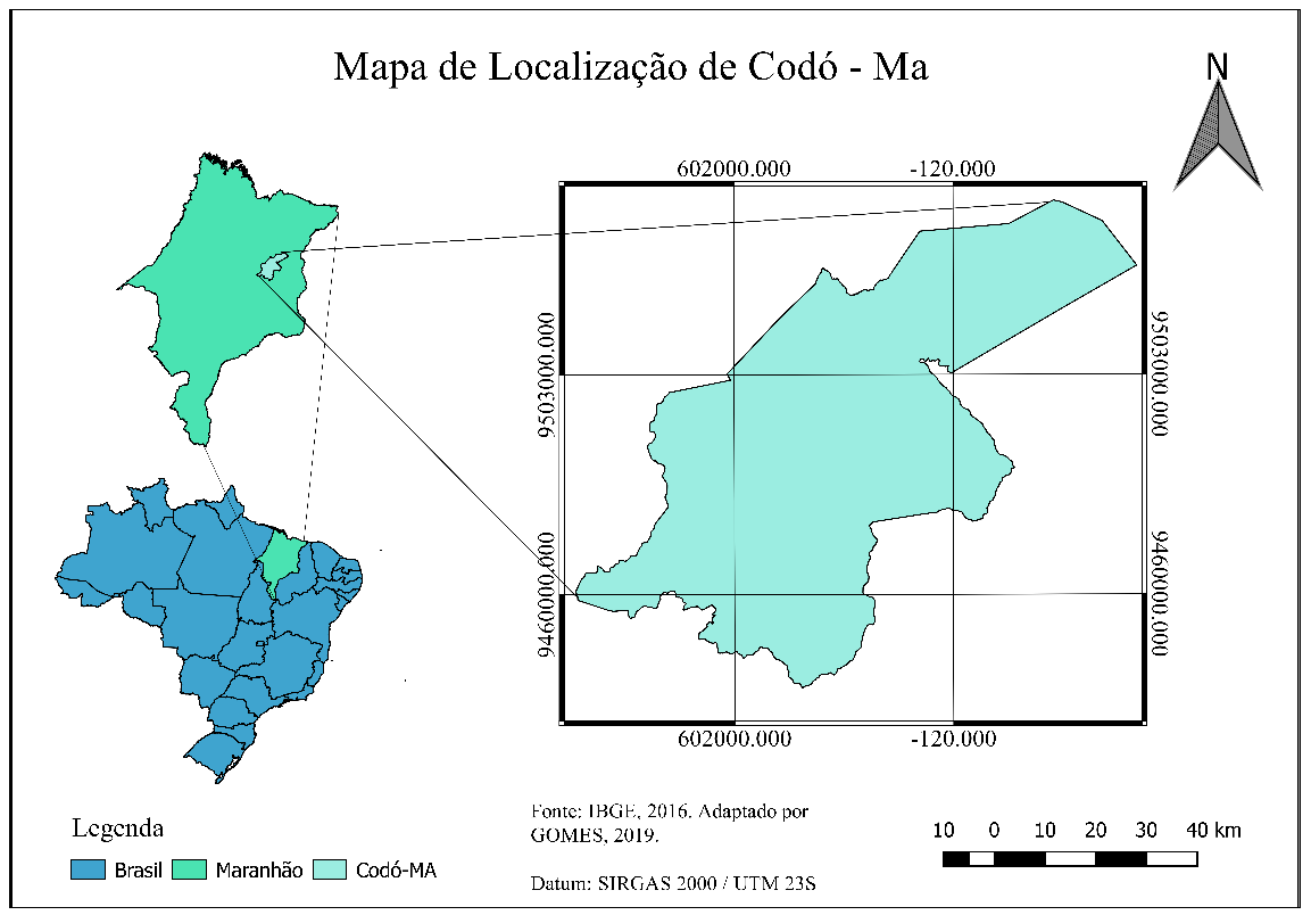

Fonte: IBGE, 2016. Adaptado por Gomes, 2019. 
O delineamento experimental utilizado foi de blocos casualizado (DBC), em esquema fatorial 3x4, sendo 3 tipos de adubos, 4 densidades e 3 repetições. Sendo dois adubos orgânicos: esterco de bovino curtido e húmus de minhoca, o qual foi produzido a partir do esterco de caprino semi-curtido, e um inorgânico, formulado à base de adubos solúveis contendo NPK. As densidades utilizadas entre linhas e entre plantas foram respectivamente: $15 \mathrm{~cm} \mathrm{x} 4 \mathrm{~cm}, 15 \mathrm{~cm} \mathrm{x}$ $7 \mathrm{~cm}, 20 \mathrm{~cm} \times 4 \mathrm{~cm}$ e a testemunha $20 \mathrm{~cm} \times 8 \mathrm{~cm}$. A testemunha refere-se ao espaçamento recomendado por Filgueira (1982), citado por Minami et., al (1998).

Antes da instalação do experimento foram retiradas amostra de solo da área experimental na profundidade de $0-20 \mathrm{~cm}$, as quais foram secas ao ar, e peneiradas em malha de $2 \mathrm{~mm}$, e em seguida foram enviadas ao laboratório de química de solos da UEMA em São Luiz - MA.

Os resultados da análise foram: $\mathrm{pH}=4,8 ; \mathrm{P}=5 \mathrm{mg} / \mathrm{dm}-3 ; \mathrm{K}=2,5 \mathrm{mmolc} / \mathrm{dm}-3 ; \mathrm{Al}=0,40$ cmolc/ $/ \mathrm{dm}^{-3} ; \mathrm{Ca}=22 \mathrm{mmolc} / \mathrm{dm}^{-3} ; \mathrm{Mg}=13 \mathrm{mmolc} / \mathrm{dm}^{-3} ; \mathrm{H}+\mathrm{Al}=2,4 \mathrm{cmolc} / \mathrm{dm}^{-3} ; \mathrm{CTC}=53,5$ mmolc $/ \mathrm{dm}^{-3} ; \mathrm{V}=46,37 \% ; \mathrm{M} . \mathrm{O}=9 \mathrm{~g} / \mathrm{dm}^{-3} . \mathrm{O}$ solo foi corrigido com calcário dolomítico (PRNT $90 \%$ ) a uma camada de $20 \mathrm{~cm}$ de incorporação.

O sistema de irrigação instalado foi por microaspersão, sendo efetuada a irrigação dos canteiros diariamente, exceto em dias de chuva.

A adubação das parcelas ocorreu aos 45 dias após a correção do solo utilizando 3 diferentes fontes de adubos minerais (Tabela 1).

Tabela 1 - Quantidade de adubo mineral em gramas (g) aplicado no plantio e cobertura.

\begin{tabular}{cccc}
\hline Época & N & P & K \\
\hline Plantio & - & $2000 \mathrm{~g}$ & $120 \mathrm{~g}$ \\
Cobertura & $804 \mathrm{~g}$ & - & $240 \mathrm{~g}$ \\
\hline Total & $\mathbf{8 0 4} \mathbf{g}$ & $\mathbf{2 0 0 0} \mathbf{~ g}$ & $\mathbf{3 6 0} \mathbf{~ g}$ \\
\hline
\end{tabular}

Fonte: UFC (1993)

A fonte adubação nitrogenada $(\mathrm{N})$ foi a uréia, sendo aplicada somente na cobertura e parcelada em duas vezes, uma aos 10 dias após o plantio e a segunda aos 20 dias; a adubação fosfatada (P) teve como fonte o superfosfato simples, com aplicação somente no ato do plantio; e a adubação potássica (K) sendo a base de cloreto de potássio (KCL) com aplicação no plantio e cobertura, sendo somente a adubação de cobertura parcelada em duas vezes, a primeira aos 10 dias e a segunda aos 20 dias após o plantio.

Após a adubação das parcelas, sendo este feito a lanço e incorporadas a $20 \mathrm{~cm}$, foi feita a delimitação dos espaçamentos dentro das parcelas com uma fita métrica, conforme Tabela 2. 
Tabela 2 - Associação adubos versus espaçamentos.

\begin{tabular}{c|ccc}
\hline ESPAÇAMENTOS & \multicolumn{3}{c}{ ADUBOS } \\
\hline $15 \mathrm{~cm} \times 4 \mathrm{~cm}$ & Humus & NPK & E. Bovino \\
$15 \mathrm{~cm} \times 7 \mathrm{~cm}$ & $\mathrm{~T} 1$ & $\mathrm{~T} 5$ & $\mathrm{~T} 9$ \\
$20 \mathrm{~cm} \times 4 \mathrm{~cm}$ & $\mathrm{~T} 2$ & $\mathrm{~T} 6$ & $\mathrm{~T} 10$ \\
$20 \mathrm{~cm} \times 8 \mathrm{~cm}$ & $\mathrm{~T} 3$ & $\mathrm{~T} 7$ & $\mathrm{~T} 11$ \\
\hline
\end{tabular}

$\mathrm{T}^{*}:$ tratamentos.

O plantio do rabanete foi realizado por sementes, no sistema de semeadura direta, colocando de 3 a 4 sementes por cova, conforme os tratamentos descritos na Tabela 2, com três repetição para cada tratamento. A germinação das sementes ocorreu no $4^{\circ}$ dia após o plantio, sendo o desbaste efetuado quando as plantas apresentaram de duas a três folhas permanentes, deixando apenas uma planta por cova. Fora realizado ainda capinas manuais, semanalmente, retirando-se as plantas invasoras afim de evitar competição por nutrientes e espaço.

A colheita foi realizada 30 dias após a semeadura, no qual foram coletados 10 plantas de cada parcela e destas, os parâmetros analisados foram: Diâmetro da raiz (DR) sendo a aferição feita com um paquímetro digital; produtividade total de raiz (PTR) obtido a partir do peso total de todas as raízes; Produtividade comercial de raiz (PCR) foram pesadas apenas as raízes que apresentavam-se em bom estado para comercialização, sem rachaduras e má formação.

Após a obtenção dos dados as médias dos tratamentos foram submetidas a análise de variância pelo teste $\mathrm{F}$ e no caso de significância pelo teste de Tukey à $1 \%$ de significância, utilizando o programa ASSISTAT.

\section{Resultados e Discussão}

Neste estudo observou-se que houve efeito significativo dos diferentes espaçamentos e adubos, ou seja, tanto o espaçamento, quanto os adubos tiveram influência sobre os parâmetros avaliados. No entanto, a interação entre os fatores foi significativa somente para diâmetro de raiz de acordo com quadro da análise de variância (Quadro 1).

Quadro 1 - Valores de F para produtividade total de raiz (PTR); Produtividade comercial de raiz (PCR) e diâmetro de raiz (DR) de rabanete. Codó - MA, IFMA, 2019.

\begin{tabular}{ccccc}
\hline FV & GL & PTR & PCR & DR \\
\hline Espaçamento (F1) & 3 & $7.0093 * *$ & $17.0867 * *$ & $83.9524 * *$ \\
Adubos (F2) & 2 & $30.2259 * *$ & $64.3533 * *$ & $11.4890 * *$ \\
\hline Inter. (F1 X F2) & 6 & $1.0071 \mathrm{~ns}$ & $0.9677 \mathrm{~ns}$ & $6.0524 * *$ \\
\hline
\end{tabular}




\begin{tabular}{ccccc}
\hline $\begin{array}{c}\text { Tratamentos } \\
\text { Resíduo }\end{array}$ & 11 & $7.9566 * *$ & $16.8884 * *$ & $28.2863 * *$ \\
\hline Total & 34 & 35 & & \\
\hline
\end{tabular}

** significativo ao nível de $1 \%$ de probabilidade $(\mathrm{p}<.01)$; ns não significativo $(\mathrm{p}>=.05)$.

Nos estudos de Costa et. al., (2006), trabalhando com diferentes doses e fontes de adubos orgânicos na cultura do rabanete, observaram que não houve interação entre os fatores produção total e comercial de raízes. Já nos estudos feitos por Melo et al., (2014), com adubos orgânicos de origem vegetal e animal observou-se interação significativa a $1 \%$ de probabilidade quanto a produtividade comercial de raiz determinada a partir da massa fresca de raízes das plantas da área útil livres de rachaduras, não isoporizadas com diâmetro $\geq 20 \mathrm{~mm}$.

Vitti et al., (2007) e Vitória et al., (2003), utilizando o esterco bovino no cultivo do rabanete, observaram que houve aumento significativo no diâmetro de raiz do rabanete. Nos estudos de Junior et al., (2013) e Linhares et al., (2011) analisando os efeitos da incorporação de adubos orgânicos nas doses de 15,6 t/ha e 12,0 t/ha no cultivo do rabanete, obtiveram resultados aproximados de 5,22 e 4,5 cm para o diâmetro de raiz.

Sendo os valores de F significativos para os parâmetros avaliados, foi realizado o teste de Tukey para comparação das médias ao nível de 1\% de significância (Tabela 6).

Tabela 6 - Valores de produtividade total de raiz (PTR); produtividade comercial de raiz (PCR); e diâmetro de raiz (DR) de rabanete. Codó - MA, IFMA, 2019.

\begin{tabular}{cccc}
\hline Fatores & $\begin{array}{c}\text { PTR } \\
\text { (g planta-1) }\end{array}$ & $\begin{array}{c}\text { PCR } \\
\text { (g planta-1) }\end{array}$ & $\begin{array}{c}\text { DR } \\
(\mathbf{m m})\end{array}$ \\
\hline Espaçamentos (Fator 1) & & & \\
$15 \mathrm{~cm} \times 4 \mathrm{~cm}$ & $15.02256 \mathrm{~b}$ & $13.58233 \mathrm{~b}$ & $29.43667 \mathrm{c}$ \\
$15 \mathrm{~cm} \times 7 \mathrm{~cm}$ & $15.87044 \mathrm{ab}$ & $14.49833 \mathrm{~b}$ & $33.40222 \mathrm{~b}$ \\
$20 \mathrm{~cm} \times 4 \mathrm{~cm}$ & $15.43478 \mathrm{~b}$ & $13.73089 \mathrm{~b}$ & $29.98111 \mathrm{c}$ \\
$20 \mathrm{~cm} \times 8 \mathrm{~cm}$ & $17.37678 \mathrm{a}$ & $15.96556 \mathrm{a}$ & $38.04222 \mathrm{a}$ \\
\hline Adubos (Fator 2) & & & \\
Húmus & $17.91925 \mathrm{a}$ & $16.49850 \mathrm{a}$ & $34.15667 \mathrm{a}$ \\
NPK & $14.27150 \mathrm{c}$ & $12.97483 \mathrm{c}$ & $31.76500 \mathrm{~b}$ \\
E. Bovino & $15.58767 \mathrm{~b}$ & $13.85950 \mathrm{~b}$ & $32.22500 \mathrm{~b}$ \\
\hline CV\% & $\mathbf{7 . 3 1}$ & $\mathbf{5 . 4 8}$ & $\mathbf{3 . 9 6}$
\end{tabular}

Médias seguidas pela mesma letra não diferem estatisticamente entre si. Foi aplicado o Teste de Tukey ao nível de $1 \%$ de probabilidade.

De acordo com os resultados do teste, observou-se que para todos os parâmetros, produtividade total de raiz e diâmetro de raiz o espaçamento $20 \mathrm{~cm} \mathrm{x} 8 \mathrm{~cm}$, se mostrou o mais eficiente, seguido do espaçamento $15 \mathrm{~cm}$ x $7 \mathrm{~cm}$. Já na produtividade comercial das raízes o espaçamento $20 \mathrm{~cm}$ x $8 \mathrm{~cm}$ também mostrou - se mais eficaz, sendo que os demais foram estatisticamente iguais pelo teste de Tukey a $1 \%$ de probabilidade. 
O melhor desempenho do rabanete nestes espaçamentos $(20 \mathrm{~cm}$ x $8 \mathrm{~cm} ; 15 \mathrm{~cm} \mathrm{x} 7 \mathrm{~cm})$ pode ser explicado pela menor competição por nutrientes entre plantas na fileira, visto que, mediante análise estatística, não houve diferença significativa entre os espaçamentos de linhas testadas para nenhuma das características analisadas, sendo significativa apenas a competição entre plantas na linha.

Resultado semelhante foi obtido por Minami et. al., (1998), estudando o efeito dos espaçamentos no rabanete, verificou que não houve diferença significativa entre os espaçamentos entre linhas. sendo significativo a competição entre plantas na linha. Ele explica que isso deve ter ocorrido devido ao pequeno desenvolvimento foliar das plantas que, mesmo no menor espaçamento entre linhas, não chegou a cobrir todo o espaço entre as linhas. Houve pequeno sombreamento das plantas de uma linha por plantas de linhas adjacentes. Além disso, não deve ter havido concorrência por nutrientes e água entre plantas de linhas diferentes, pois suas raízes não exploraram a mesma área de solo.

A produção total de raízes por parcela não foi afetada significativamente nem pelos espaçamentos entre linhas nem entre plantas, ao contrário da produção média de raízes. Plantas mais espaçadas na linha produziram raízes maiores e, portanto, de maior valor comercial. Os resultados concordam com os de Weston (1982), que obteve raízes mais desenvolvidas em plantas espaçadas por 3,8 cm entre si, em comparação com o espaçamento de 2,6 cm.

Quanto aos diferentes adubos usados na pesquisa, o humus de minhoca apresentou valores superiores para todos os parâmetros, seguido do esterco bovino com as segundas melhores médias para todos os parâmetros. A adubação com NPK foi a que se mostrou menos eficaz com valores médios inferiores aos demais adubos orgânicos. Segundo Bonela (2017), o crescimento e desenvolvimento de raízes de rabanete está relacionado com o teor de matéria orgânica do solo e principalmente com suas características físicas, como teores de argila, que influenciam diretamente na porosidade, proporcionando melhores rendimentos.

Nos estudos de Rodrigues et al., (2013) verificou-se maior influência na produção de biomassa da parte aérea do rabanete quando utilizado fertilizantes orgânicos do que utilizandose fertilizantes minerais. Nessa perspectiva, Freddi et al. (2008), explica que o crescimento e desenvolvimento do sistema radicular e da parte aérea estão associados às boas condições físicas do solo. Os adubos orgânicos aplicados, independente da origem, podem ter proporcionado a melhoria nas características físicas do solo, fazendo com que os mesmos proporcionassem resultados superiores. Esse comportamento deve-se não apenas ao fato do 
fornecimento de nutrientes, como na adubação mineral, mas também pelos efeitos benéficos na agregação, porosidade, retenção e infiltração de água no solo.

No gráfico 1 são representados as médias de produtividade total e comercial para cada tratamento.

Gráfico 1 - Relação Produtividade Total x Produtividade Comercial em kg/m²

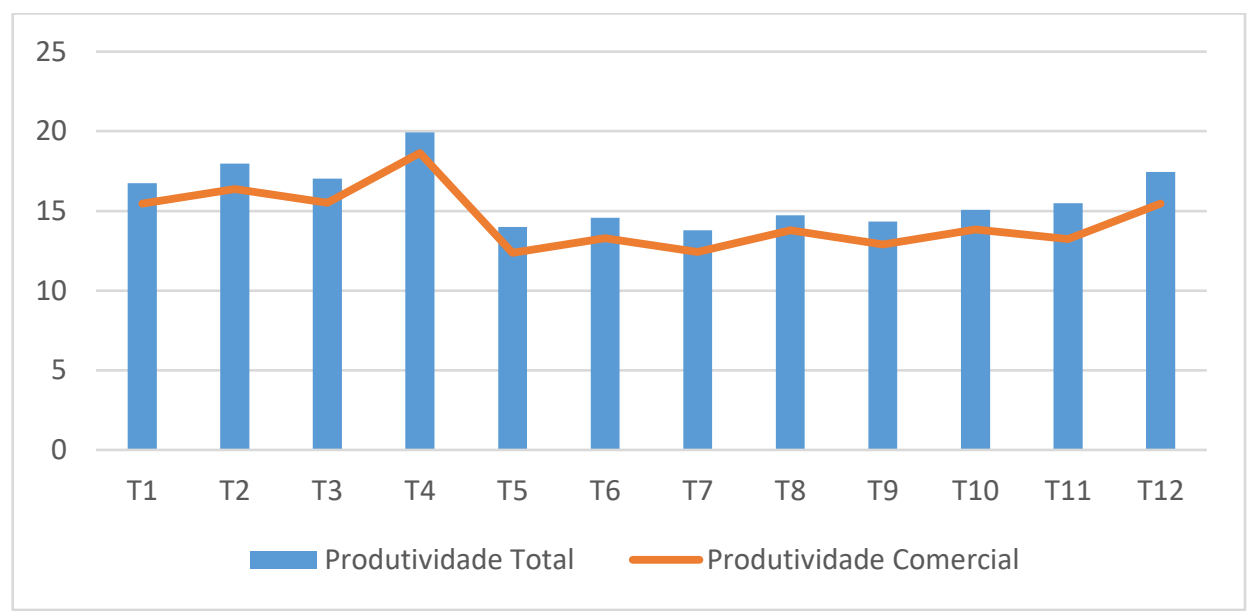

Fonte: Elaborado pelo autor.

Observa-se que as médias de produtividade total de raiz, foram melhores na adubação com humus, seguida da adubação com esterco bovino. A produtividade comercial das raízes mostrou valores bem próximos ao de produtividade total, resultado estes excelentes, uma vez que de uma amostra de 10 plantas retirada de cada parcela para análise, $80 \%$ destas apresentavam padrão adequado a comercialização (Raízes sem deformidade e sem rachaduras).

Embora o cultivo do rabanete tenha ocorrido no período indicado para a região nordeste que vai de maio a julho que coincide com o período chuvoso, uma vez que a cultura é sensível a estresse hídrico e altas temperaturas, a presença de raízes rachadas e isoporizadas é fator comum que acomete a cultura do rabanete.

As maiores médias obtidas no parâmetro diâmetro de raiz também constaram das parcelas que receberam adubação com húmus. Quanto ao espaçamento, observa-se que os maiores espaçamentos entre plantas, testados na pesquisa $(20 \mathrm{~cm} \mathrm{x} 8 \mathrm{~cm} \mathrm{e} 15 \mathrm{~cm} \mathrm{x} 7 \mathrm{~cm})$ foram os que proporcionaram as melhores médias.

\section{Conclusão}

De acordo com os resultados obtidos e discutidos a utilização do húmus de minhoca com o espaçamento $20 \mathrm{~cm}$ × $8 \mathrm{~cm}$ influenciam para o maior desenvolvimento e produtividade do rabanete nas condições em que o experimento foi conduzido. 


\section{Referências}

ASSIS, M. P. de.; VALLONE, H. S.; SENE, M.G. T. de.; MELLO, I. E. de.; OLIVEIRA, J. N. S.; Produção de rabanete em função de doses de composto orgânico na semeadura. Seminário de pesquisa e inovação tecnologia (SEPIT), (2016).

BATISTA, M. A. V. Adubação verde na produtividade, qualidade e rentabilidade de beterraba e rabanete. 2011. 123 f. Tese (Doutorado em Agronomia: Fitotecnia) Universidade Federal Rural do Semiárido (UFERSA), Mossoró, 2011.

BONELA, G. D.; SANTOS, W. P.; SOBRINHO, E.A; GOMES, E. J. C. Produtividade e qualidade de raízes de rabanete cultivadas sob diferentes fontes residuais de matéria orgânica. Revista Brasileira de Agropecuária Sustentável (RBAS), v.7, n.2, p.66-74, junho, 2017.

CERQUEIRA JÚNIOR, E. P. de et al. Avaliação do efeito da adubação verde com flor-deseda (calatropisprocera) na cultura do rabanete (Raphanus sativus L.), em Período Seco. In: XIII Jornada de Ensino, Pesquisa e Extensão - JEPEX, 2013, Recife. Disponível em: <http://www.eventosufrpe.com.br/2013/ cd/resumos/R0626-1.pdf>. Acesso em: $19 \mathrm{de}$ fevereiro de 2018.

COSTA CC; OLIVEIRA CD; SILVA CJ; TIMOSSI PC; LEITE IC. 2006. Crescimento, produtividade e qualidade de raízes de rabanete cultivadas sob diferentes fontes e doses de adubos orgânicos. Horticultura Brasileira,

CUSTÓDIO, A. M.; Teor de vitamina c, acúmulo de minerais e produção de rabanetes submetidos a diferentes adubações. Dissertação (mestrado) - Universidade Federal de Viçosa. Viçosa, MG, 2014.

EDVAN, R. L.; CARNEIRO, M. S. S. Uso da digestiva bovina como adubo orgânico. Revista Brasileira de Tecnologia Aplicada nas Ciências Agrárias. Guarapuava, v.4, n.2, p.211-225, 2011.

EMBRAPA - Hortas: o produtor pergunta, a Embrapa responde / editores técnicos, Gilmar Paulo Henz, Flávia Aparecida de Alcântara. - Brasília, DF: Embrapa Informação Tecnológica. 237; $22 \mathrm{~cm}$ - (Coleção 500 perguntas, 500 respostas) 2009.

FILGUEIRA, F. A. R.: Manual de olericultura: cultura e comercialização de hortaliças. 2. Ed. rev. São Paulo: Editora Agronômica Ceres, 1982.

FREDDI, O. da S.; FERRAUDO, A.S.; CENTURION, J.F. Análise multivariada na compactação de um latossolo vermelho cultivado com milho. Revista Brasileira de Ciência do Solo, 32(3):953-961, 2008. 
FREITAS, B. V. Resposta agroeconômica da rúcula adubada com húmus de minhoca sucedida pelo cultivo de rabanete. MOSSORÓ-RN 2017.

INSTITUTO BRASILEIRO DE GEOGRAFIA E ESTATÍSTICA (IBGE). Censo agropecuário. 2006.

ISHERWOOD, K. F. Mineral Fertilizer Use and the Environment. Paris: IFA (International Fertilizer Industry Association) UNEP (United Nations Environment Programme), 2000.

KIEHL, E.J. Novos fertilizantes orgânicos. Piracicaba: 1ª edição do autor. 248 p, 2010.

LINHARES PCF; SILVA ML; PEREIRA MSF; BEZERRA AHK; PAIVA ACC. Quantidades e tempos de decomposição da flor-de-seda no desempenho agronômico do rabanete. Revista Verde 6: 168-173.2011.

MEDEIROS, G. K. C. Q.; Estudo comparativo da influência da adubação química e orgânica nos parâmetros químicos do solo de cultivo das hortaliças jambu (Acmella Jansen) e coentro (Coriandrum sativum L). Dissertação (Mestrado em Ciências Ambientais) - Universidade do Estado do Pará, Centro de Ciências Naturais e Tecnologia, Belém, 2014

MELO, FLÁVIA NAIRLA BARBOSA DE; LINHARES, PAULO CÉSAR FERREIRA; SILVA, EMERSON BRUNO RODRIGUES DA; NEGREIROS, ANDRÉIA MITSA PAIVA DE; NETO, JOSÉ BEZERRA DANTAS. Desempenho produtivo do rabanete sob diferentes quantidades de palha de carnaúba mais esterco bovino em cobertura. ACSA Agropecuária Científica no Semi - Árido, V. 10, n. 3, 2014.

MINAMI, K.; CARDOSO, A. I. I.; COSTA, F.; DUARTE, F. R.: Efeito Do Espaçamento Sobre A Produção Em Rabanete. Bragantina vol. 57 n. 1 Campinas, 1998

MORAES, I. V. M. de.; Dossiê técnico: cultivo de hortaliças; novembro de 2006.

MOREIRA, J. L. A.; CARRERA, M.; MANTOVANI, J. R.; AUGUSTO, H. S.; PAULA, D. W. de.; MARQUES, D. J.; Atributos de fertilidade e produção de hortaliças folhosas em solos adubados com esterco bovino. XXXV Congresso Brasileiro de solo, Natal - RN; 2015.

OLIVEIRA, A. P.; BARBOSA, A. H. D.; CAVAlCANTE, L. F.; PEREIRA, W. E.; OLIVEIRA, A. N. P. Produção da batata-doce adubada com esterco bovino e biofertilizantes. Ciência e Agrotecnologia, Lavras, v. 31, n. 6, p. 1722- 1728, 2007.

OLIVEIRA, A.P.; ESPÍNOLA, F.E.J.; ARAÚJO, J.S.; COSTA, C.C. Produção de raízes de cenoura cultivadas com húmus de minhoca e adubo mineral. Horticultura Brasileira, Brasília, v. 19, n. 1, p. 77 - 80, março 2001.

OLIVEIRA, V. C.; OLIVEIRA, M. E. F.; SANTOS, R. M.; AQUINO, E. L.; SANTOS, A. R. Resposta de plantas de rúcula à adubação orgânica. Revista Cadernos de Agroecologia, Porto Alegre, v. 8, n. 2, p. 1- 5, 2013.

PASqualotto, A. T., BOtelho C.E., MENDES, A. N. G., CARVAlHO, A. M., REZENDE, R. M., HAYASHI, F.L. Caracterização do desenvolvimento inicial de cultivares de cafeeiro em diferentes espaçamentos (2014). 
REIS, F. M; VEIGA P. O. A; COUTINHO, A. L; DIAS, R. J; Bioestimulante e densidade populacional na produção de rabanete. 2010.

RODRIGUES, Jaqueline F.; REIS, Janaine M. R.; REIS, Marcelo de A.: Utilização de estercos em substituição a adubação mineral na cultura do rabanete. Revista Trópica - Ciências Agrárias e Biológicas V. 7, N.2, 2013

SILVA, A.F.A.; SOUZA, E.G.F.; BARROS JÚNIOR, A.P. et al. Desempenho agronômico do rabanete adubado com calotropisprocera (Ait.) $R$. Br. em duas épocas de cultivo. Revista Ciência Agronômica, Fortaleza, v.48, n.2, p.328-336, 2017.

SILVA, F.C.; BOARETTO, A.E.; BERTON, R.S.; ZOTELLI, H.B.; PEXE, C.A.; BERNARDES, H.M. Efeito de lodo de esgoto na fertilidade de um Argissolo Vermelho Amarelo cultivado com cana-de-açúcar. Pesquisa Agropecuária Brasileira, v.36, n.5, p.831840, 2001.

SOUZA, J. L. RESENDE, P. Manual de horticultura orgânica. Viçosa: Aprenda Fácil, 2003.

UFC. Recomendações de adubação e calagem para o Estado do Ceará. Fortaleza, UFC, 247p. 1993.

VITÓRIA, D.; KROLOW, I.; FILHO, L. O.; MORSELLI, T. Resposta do rabanete a diferentes adubações orgânicas em ambiente protegido. In: I Congresso Brasileiro de Agroecologia, IV Seminário Internacional sobre Agroecologia, V Seminário Estadual sobre Agroecologia. Resumos. Porto Alegre, 2003.

VITTI, M.R.; VIDAL, M.B.; MORSELLI, T.B.G.; FARIA, J.L.C. Resposta do rabanete a adubação orgânica em ambiente protegido. Revista Brasileira de Agroecologia, 2(1): 11581161, 2007.

WESTON, G. The effects of crowding, daminazide and red to far-red ratios of light on the growth of radish (Raphanus sativus L.). Journal of Horticultural Science, Ashford, 57: 373376, 1982. 